\title{
The Effect of Heat Treatment on the Thermal Expansion Behavior of Electroformed Nano-crystalline Fe-42 wt\%Ni Alloy
}

\author{
Minsu Lee, Yunho Han, Tai Hong Yim* \\ Surface Technology R\&BD Group, Korea Institute of Industrial Technology (KITECH), 7-47 Songdo-Dong, \\ Yeonsu-Gu, Incheon, 406-840, Korea
}

(Received December 8, 2014 ; revised December 17, 2014 ; accepted December 18, 2014)

\begin{abstract}
Fe-Ni has been of great interest because it is known as one of low thermal expansion alloys as various application areas. This alloy was fabricated by electroforming process, and effect of heat treatment on thermal expansion and hardness was investigated. Nano-crystalline structure of $13.3-63.5 \mathrm{~nm}$ in size was observed in the as-deposited alloy. To investigate the effect of heat treatment on grain growth and mechanical/thermal properties, we conducted hardness and coefficient of thermal expansion (CTE). From this, we confirmed these properties were varied by heat treatment. In this nano-crystalline alloy, we could observe abnormal behavior in thermal expansion between $350-400^{\circ} \mathrm{C}$. Additionally, an abrupt change in hardness has also been observed. However, once the grains grow up to micro-sized the mechanical and thermal properties mentioned above were stabilized similar to those of bulk alloys due to heat treatment.
\end{abstract}

Keywords : Electroforming, Iron-nickel alloy, Grain growth, Thermal expansion behavior

\section{Introduction}

The thermal expansion behavior of nano-crystalline materials can occur as thermal expansion at the crystal grain and at the grain boundary. Although thermal expansion at the crystal grain boundary of nano-crystalline materials is not much different than that of existing bulk materials, it has been reported that thermal expansion in the crystal grain boundary is larger than that of the crystal grain ${ }^{1)}$. Grimmet et al. reported that the coefficient of thermal expansion (CTE) of Fe-Ni alloy with $60-70$ wt.\% Fe prepared by electrodeposition was higher than that of the cast alloy. They explained that this thermal expansion behavior occurs because electroformed $\mathrm{Fe}-\mathrm{Ni}$ alloy consists of dual phases, $\mathrm{FCC}$ and $\mathrm{BCC}^{2)}$. However, according to a report by Turi and Erb, no difference was observed between the thermal expansion

*Corresponding Author : Tai Hong Yim

Surface Technology R\&BD Group, Korea Institute of Industrial Technology (KITECH)

E-mail : thyim@kitech.re.kr behavior of electroformed nano-crystalline $\mathrm{Ni}$ as compared with that of bulk materials ${ }^{3}$. As has been explained, the thermal expansion behaviors of electroformed $\mathrm{Ni}$ alloys are reportedly different from each other.

Electroforming is a process that employs technology similar to that used for electroplating, but is used for manufacturing metallic articles, rather than as a means of producing surface coatings ${ }^{4)}$. In electroforming, a part is produced by the deposition of metal ions onto a pre-shaped cathode mandrel. This process has excellent repetitive accuracy and high fidelity of shape reproduction from the mandrel. These unique advantages of the electroforming process are of great importance to the manufacturing of parts with complex shapes and precise dimensions ${ }^{5}$.

The present study investigated the effect of the grain growth of nano-crystalline $\mathrm{Fe}-42 \mathrm{wt} \% \mathrm{Ni}$ alloy on thermal expansion behavior and hardness.

\section{Experimental}

Plate shape nano-crystalline $\mathrm{Fe}-42 \mathrm{wt} \% \mathrm{Ni}$ alloy 
with was prepared by the electroforming process. A surfactant, a brightener, and other additives were used for the electrolyte solution. Iron (II) chloride and nickel (II) sulfamate were added with stirring to the solution. Stainless Steel 304 plate was used as the cathode on which the metal was electrodeposited, and Ni plate was used as the anode.

To observe hardness changes with the grain growth of $\mathrm{Fe}-42 \mathrm{wt} \% \mathrm{Ni}$ alloy, the electroformed alloy plates were heat-treated. Heating temperatures were 300 , $350,375,400,600$ and $800^{\circ} \mathrm{C}$ and heating time was $1 \mathrm{hr}$. Heat-treatments were carried out in high purity (99.999\%) hydrogen atmosphere. The grain size of the heat treated nano-crystalline $\mathrm{Fe}-42 \mathrm{wt} \% \mathrm{Ni}$ alloy was calculated by the Scherrer equation, since sample preparation for TEM was difficult due to the high hardness. FE-SEM and optical microscope were used to observe the microstructure of the electroetched alloys and grain size determination was carried out using the lineal intercept procedure in accordance with ASTM E112 ${ }^{6}$. The thermal expansion behavior of the $\mathrm{Fe}-42 \mathrm{wt} \% \mathrm{Ni}$ alloy was observed by TMA. The changes of CTE were measured while the alloy was heating with a heating rate of $5^{\circ} \mathrm{C} / \mathrm{min}$ from room temperature to $520^{\circ} \mathrm{C}$. Hardness of as-deposited or heat-treated samples was measured by Vicker's Hardness tester.

\section{Results and Discussion}

Figure 1 shows the X-ray diffraction patterns of the Fe- $42 \mathrm{wt} \% \mathrm{Ni}$ alloys. From the observed XRD peak, it is clear that the electroformed $\mathrm{Fe}-42 \mathrm{wt} \% \mathrm{Ni}$ alloy consists of FCC phase and BCC phase. However, as the temperature increased, the peak of the FCC phase became more prominent. The BCC phase peak disappeared when the sample was treated at a temperature higher than $600^{\circ} \mathrm{C}$. The Scherrer equation (1) is related to the diffraction peak broadening, and was used to calculate the grain size of the Fe- $42 \mathrm{wt} \% \mathrm{Ni}$ alloy. Here, $\mathrm{t}$ is the diameter of grain and $\mathrm{B}$ is the width of diffraction line broadening at half of its maximum intensity.

$$
\mathrm{t}=\frac{k \times \lambda}{B \cos \theta_{B}}
$$

The grain size calculation results from each orientation using the Scherrer equation are presented in Table 1. The size of the grain in the electroformed alloy before heat treatment was calculated to be in the range of $13.3-63.5 \mathrm{~nm}$ according to the crystal

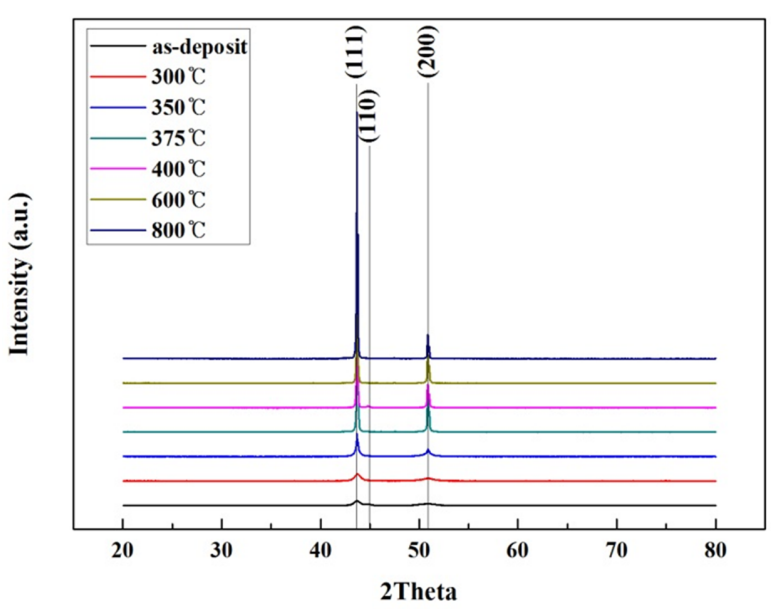

Fig. 1. XRD patterns of $\mathrm{Fe}-42 \mathrm{wt} \% \mathrm{Ni}$ alloys.

Table 1. Grain size of $\mathrm{Fe}-42 \mathrm{wt} \% \mathrm{Ni}$ by Scherrer equation

\begin{tabular}{|c|c|c|c|}
\hline \multirow{2}{*}{$\begin{array}{c}\text { Annealing } \\
\text { Temp. }\left({ }^{\circ} \mathrm{C}\right)\end{array}$} & \multicolumn{3}{|c|}{ Grain size $(\mathrm{nm})$ of each phase } \\
\cline { 2 - 4 } & $\begin{array}{c}\text { FCC } \\
(111)\end{array}$ & $\begin{array}{c}\text { FCC } \\
(200)\end{array}$ & $\begin{array}{c}\text { BCC } \\
(110)\end{array}$ \\
\hline before & 25.3 & 13.3 & 63.5 \\
\hline 300 & 19.5 & 25.7 & - \\
\hline 350 & 103.7 & 71.1 & - \\
\hline 375 & 103.7 & 85.3 & - \\
\hline 400 & 103.7 & 85.3 & 104.1 \\
\hline 600 & 103.7 & 106.6 & - \\
\hline 800 & 103.7 & 142.1 & - \\
\hline
\end{tabular}

orientation. The grain size increased as heating temperature increased. Results show that grain growth was not prominent until the temperature exceeded $375^{\circ} \mathrm{C}$.

In general cases, because the FWHM (full width at half maximum) actually becomes 0 as the grain size exceeds $100 \mathrm{~nm}$, calculating grain size with the Scherrer equation is not a proper approach for heattreated alloys with grains larger than $100 \mathrm{~nm}^{7}$. Because the grain sizes of the (111)//alloy plate plane in the present study were the same within the temperature range of $350^{\circ} \mathrm{C}$ to $800^{\circ} \mathrm{C}$, it was necessary to use another approach to analyze the grain size of the alloy heat-treated above $350^{\circ} \mathrm{C}$.

Therefore, this study adopted the method of using optical or SEM images for analysis of grain size. The lineal intercept method was used to analyze the grain sizes. To easily find a clear part of an electrolytic etched sample for use in the optical microscope, SEM images were used for verification. Fig. 2 shows the optical micrographs and SEM images of alloy heat-treated at 400,600 and $800^{\circ} \mathrm{C}$. The magnification of the optical micrographs is 1,000. The 


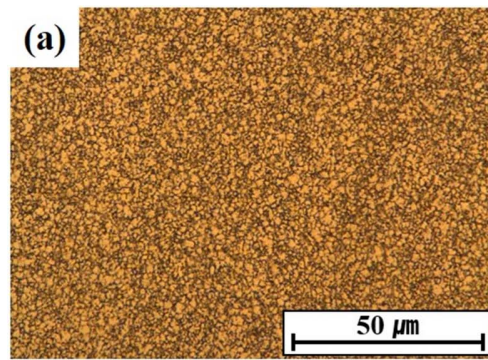

(d)

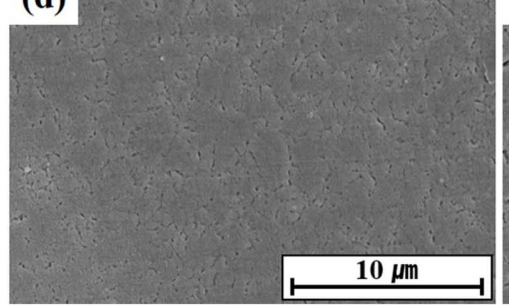

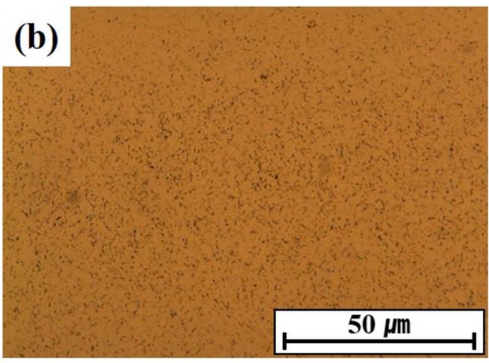

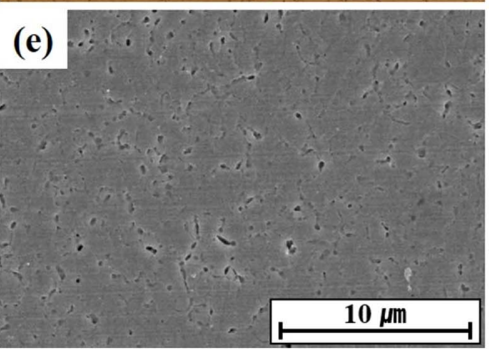

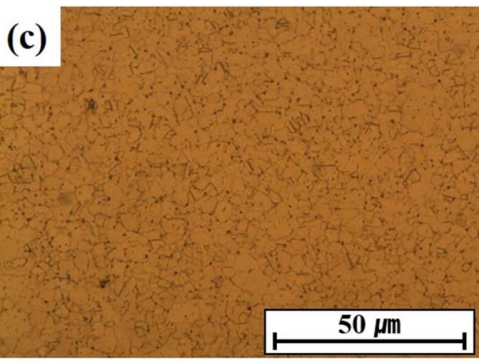

(f)
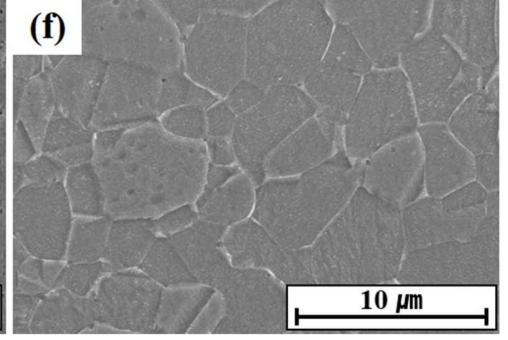

Fig. 2. Surface morphology according to heat-treatment temperature. Optical microscope: (a) $400^{\circ} \mathrm{C}$, (b) $600^{\circ} \mathrm{C}$, (c) $800^{\circ} \mathrm{C}$. SEM image: (d) $400^{\circ} \mathrm{C}$, (e) $600^{\circ} \mathrm{C}$, (f) $800^{\circ} \mathrm{C}$.

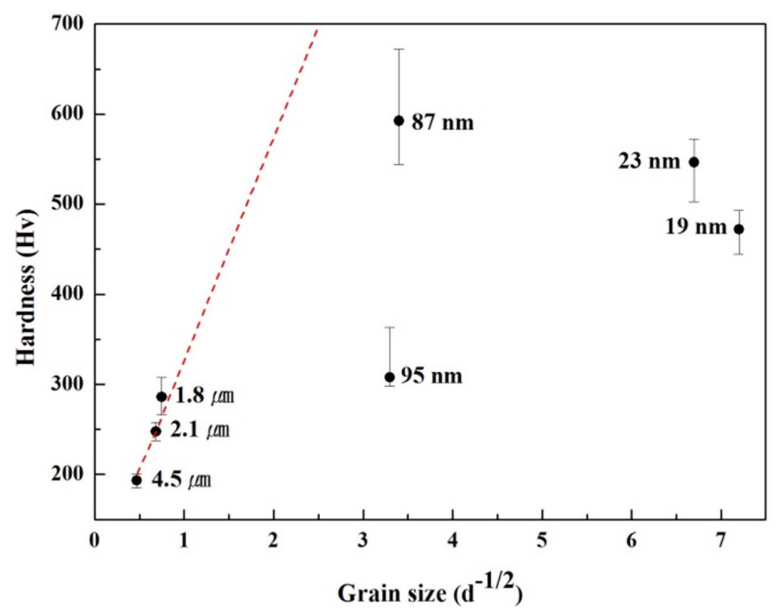

Fig. 3. Vicker's hardness according to grain size $(d=$ grain size, $\mu \mathrm{m})$.

magnification of the SEM image is 5,000. It can be observed that the grain size continuously grows as the heating temperature increases. The grain sizes of alloy heat-treated at $400^{\circ} \mathrm{C}$ and $600^{\circ} \mathrm{C}$ were $1.8 \mu \mathrm{m}$ and $2.1 \mu \mathrm{m}$. The grain size of alloy heat-treated at $800^{\circ} \mathrm{C}$ was $4.5 \mu \mathrm{m}$ according to the SEM image and $4.3 \mu \mathrm{m}$ by optical micrograph.

The hardness change based on the grain size, as shown in Fig. 3. For the alloy heat-treated at $400^{\circ} \mathrm{C}$, grains which were smaller than $1 \mu \mathrm{m}$ might have been easily dissolved during the etching process. This introduced the possibility that the grain size calculated by the lineal intercept method may not be correct. So the value was recalculated by the HallPetch equation (2) which was obtained using the grain size and hardness values of the alloys heat- treated at $600^{\circ} \mathrm{C}$ and $800^{\circ} \mathrm{C}$.

$$
H_{v}=H_{o}+k \cdot d^{-1 / 2}
$$

In this study, $\mathrm{H}_{\mathrm{o}}$ and $\mathrm{k}$ are 74.6 and 252.5 , so, $\mathrm{Hv}$ $=74.6+252.5 \cdot \mathrm{d}^{-1 / 2}$. The recalculated grain sizes of the alloys heat-treated at $350^{\circ} \mathrm{C}$ and $375^{\circ} \mathrm{C}$ were 0.23 $\mu \mathrm{m}$ and $1.17 \mu \mathrm{m}$. The hardness change with grain size is consistent with the Hall-Petch equation if the grain size is micrometer scale. The nano structure of $\mathrm{Fe}-42 \mathrm{wt} \% \mathrm{Ni}$ alloy may evolve to a sub-micro or micro structure during heat-treating between $350^{\circ} \mathrm{C}$ and $370^{\circ} \mathrm{C}$.

Figure 4 shows the thermal expansion and CTE change of the $\mathrm{Fe}-42 \mathrm{wt} \% \mathrm{Ni}$ alloy with heating temperature. The thermal expansion of as-deposited alloys and alloys heat-treated at $400^{\circ} \mathrm{C}$ drastically changed. However, the thermal expansion behavior of alloys heat-treated above $500^{\circ} \mathrm{C}$ was similar to that of the bulk alloy. This phenomenon can be explained as a result of compositional homogenization and phase transformation, in which the dual phases with BCC and FCC transformed to single phase FCC during heat-treatment.

\section{Summary}

$\mathrm{Fe}-42 \mathrm{wt} \% \mathrm{Ni}$ alloy was prepared using the electroforming process. The results of the microstructure, hardness, and thermal expansion behavior of prepared alloys led to the following conclusions. The grain size of the as-deposited alloy calculated 

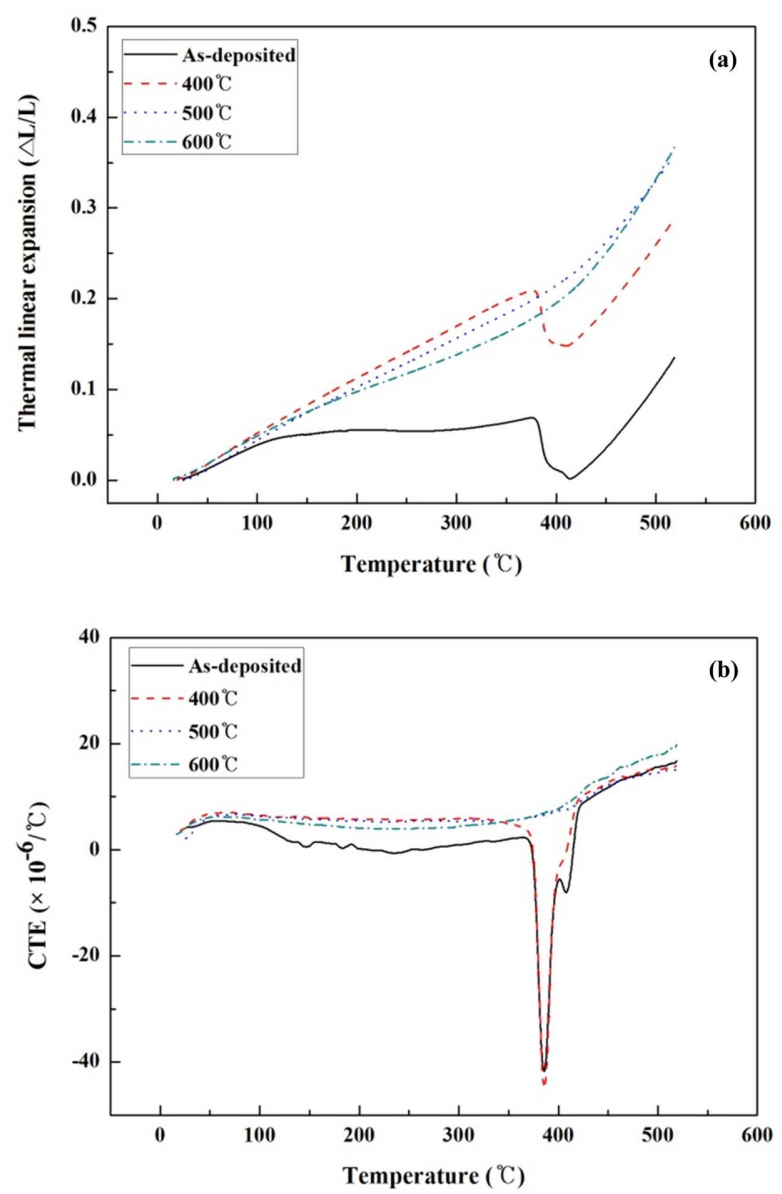

Fig. 4. Thermal expansion behavior of the electroformed Fe-42 wt\%Ni alloy, Thermal expansion, (b) Coefficient of thermal expansion (CTE).

from the XRD peak was $13.3-63.5 \mathrm{~nm}$, with mixed phase of FCC and BCC. The grain size of the alloy increased as heating temperature increased. The grain sizes of the heat-treated alloys were observed with optical micrographs and SEM images. The hardness changes in the $\mathrm{Fe}-42 \mathrm{wt} \% \mathrm{Ni}$ alloys having submicron and $\mu \mathrm{m}$ level grain sizes corresponded well with calculations obtained with the Hall-Petch equation. According to the Hall-Petch equation, the grain size of the alloy heat-treated at $350^{\circ} \mathrm{C}$ was 0.23 $\mu \mathrm{m}$, whereas the alloy heat-treated at $375^{\circ} \mathrm{C}$ showed a grain size of around $1.17 \mu \mathrm{m}$. As-deposited Fe$42 \mathrm{wt} \% \mathrm{Ni}$ alloy shrunk drastically in the temperature range between $350^{\circ} \mathrm{C}$ and $375^{\circ} \mathrm{C}$. However, this tendency disappeared after the alloy was heat-treated above $500^{\circ} \mathrm{C}$. And, stable thermal expansion behavior was observed. This resulted because the nanocrystalline structure was changed into a micro crystal structure and the dual phase was changed to a single phase of FCC. This phenomenon can be explained as a result of compositional homogenization and phase transformation, in that dual phases with $\mathrm{BCC}$ and FCC transformed to single phase FCC during heattreatment.

\section{References}

1. M. Wagner, Physical Review B, 45 (1992) 635.

2. D. L. Grimmett, M. Schwartz, K. Nobe, Journal of the Electrochemical Society, 140 (1933) 252.

3. T. Turi, U. Erb, Materials Science and Engineering A, 204 (1995) 34.

4. T. Hart, A. Watson, Metal Finishing, 98 (2000) 388.

5. D. Zhu, W. N. Lei, N. S. Qu, H. Y. Xu, Manufacturing Technology, 51 (2002) 173.

6. ASTM, Standard Test Methods for Determining Average Grain size, E112-96 (2004).

7. B. E. Warren, Progress in Metal Physics, 8 (1959) 147. 